\title{
Spinal Canal Involvement in Solitary Infantile Myofibromatosis: Case Report
}

\author{
S.N. Gautam ${ }^{1}$ Siddharth Mittal ${ }^{2}$ \\ ${ }^{1}$ Department of Neurosurgery, Government Medical College, \\ Kota, Rajasthan, India \\ 2 Department of General Surgery, Government Medical College, \\ Kota, Rajasthan, India \\ Indian J Neurosurg 2017;6:223-227.
}

Address for correspondence Siddharth Mittal, MBBS, Department of General Surgery, Government Medical College, Kota, Rajasthan, India (e-mail: nettysid@gmail.com).

\begin{abstract}
Keywords

- solitary infantile myofibromatosis

- spinal canal

- intramedullary

Infantile myofibromatosis involving the spinal canal is very rare; only 11 cases have been reported so far in the literature. The authors present a case of an 18-month-old male child who presented with the history of dribbling of urine and weakness in bilateral lower limbs since 2 months. MRI of spine revealed single intramedullary intradural space-occupying lesion (SOL) at D1 to D2.

The patient underwent laminectomy with excision of SOL with biopsy report suggestive of benign nerve sheath tumor, and immunohistochemistry report revealed desmin negative, smooth muscle actin positive, and S-100 focally positive infantile myofibromatosis. The patient gradually recovered and had a clear stream of urine with improved movements and tone of bilateral lower limbs at the time of discharge.
\end{abstract}

\section{Introduction}

Infantile myofibromatosis is the most common fibrous disorder of infancy and early childhood. It was first described by Stout ${ }^{1}$ in 1954 who named this disease congenital generalized fibromatosis. In 1981, Chung and Enzinger ${ }^{2}$ renamed the disease as infantile myofibromatosis to emphasize the microscopic resemblance to smooth muscle tissue. It may occur in two distinct forms: multicentric and solitary. In both cases, involvement of the central nervous system is unusual. Spine myofibromas are exceptional, and most of the cases reported in the literature represent secondary locations of visceral lesions. Here, we are reporting good outcome in the case of intramedullary solitary type of infantile myofibromatosis with no visceral involvement.

\section{Case Report}

\section{History and Examination}

An 18-month-old male child presented with history of dribbling of urine and weakness in bilateral lower limbs noticed by his parents since about 2 months for which the patient underwent MRI scan of spine.

received

April 9, 2015

accepted

September 17, 2016

published online

August 29, 2017
MRI revealed a single intradural intramedullary spaceoccupying lesion at D1 to D2 (see - Fig. 1). The patient was then referred to Department of Neurosurgery, M.B.S Hospital, Kota for further management.

The X-ray of long bones, blood investigations, and ultrasonogram of abdomen and pelvis were normal and showed no apparent visceral lesions. Clinically, the child had normal growth with normal body weight but had paraparesis (power $1 / 5$ ) with sluggish deep tendon reflexes and intact anal tone.

\section{Operative Course}

C-7 to D-2 laminectomy was done under general anesthesia after localizing D1 in prone position. Dura was identified and midline cordotomy was done with complete excision of encapsulated intramedullary SOL of $\sim 2 \times 1.4 \mathrm{~cm}$ in size.

\section{Postoperative Course}

On the first postoperative day, the patient was taking oral feeds and passed stools. On the second postoperative day, a catheter free trail was given and a clear stream of urine with improved motor power of bilateral lower limbs

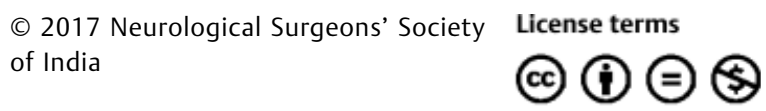

DOI https://doi.org/

10.1055/s-0036-1596041. ISSN 2277-954X. 

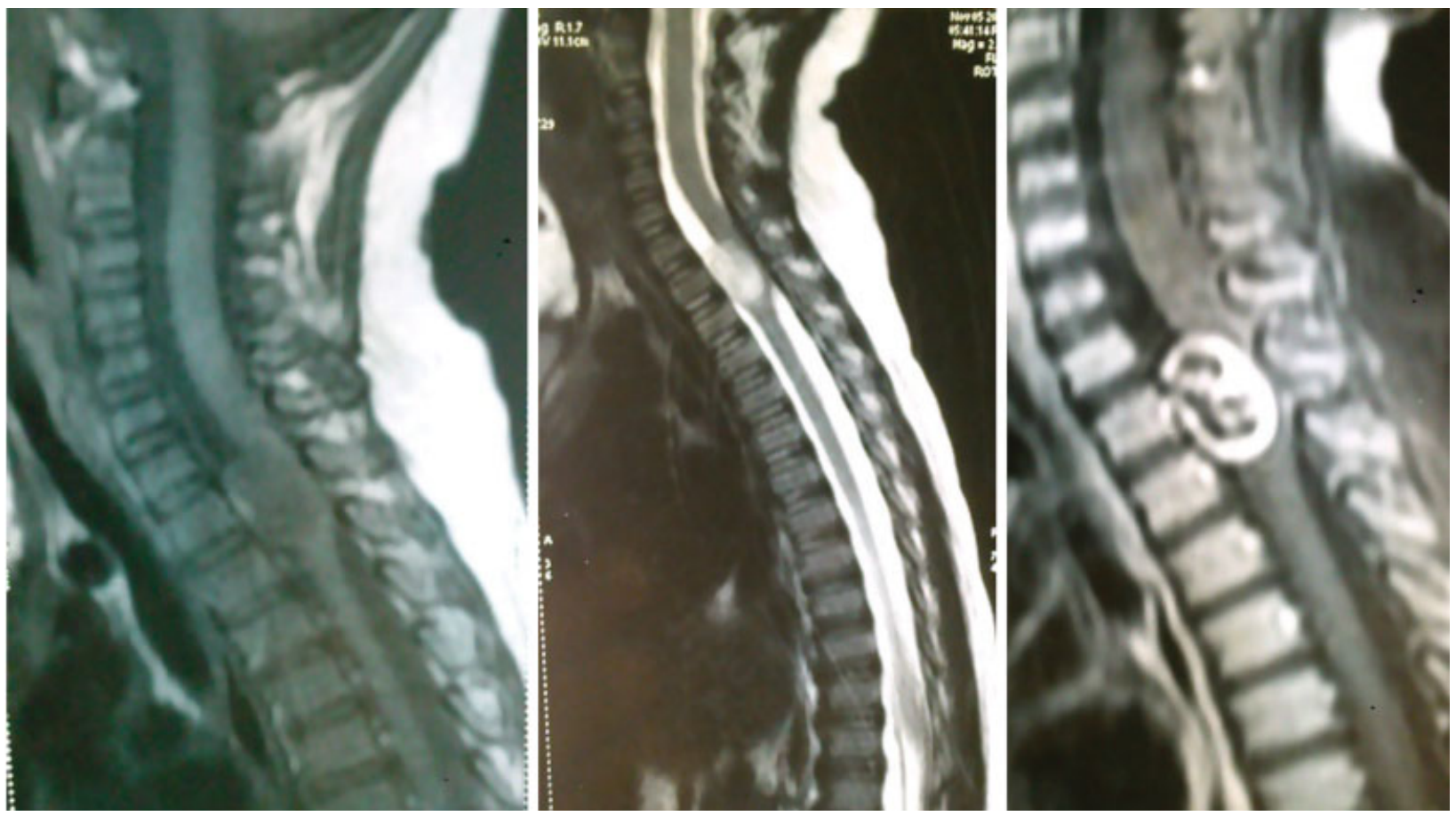

Fig. 1 Preoperative MRI images.

(MRC grade 2/5) was observed. The patient gradually recovered and was discharged on 14th postoperative day. The patient was under regular follow-up and within a span of 2 months was able to walk with support.

\section{Histopathology}

Encapsulated SOL was sent for histopathological examination which revealed well-circumscribed spindle cell tumor composed of oval to elongated to spindle cells arranged in sheets. Neoplastic cells were desmin negative (see - Fig. 2), smooth muscle actin positive (see - Fig. 3),
S-100p focally positive, KI-67 positive, 2 to $3 \%$, PAN cytokeratinnegative suggestive of infantile myofibromatosis (see - Fig. 4).

\section{Discussion}

Infantile myofibromatosis involving the spinal canal is very rare; 11 cases have been reported so far in the literature including 4 cases of the solitary form and a single case of intramedullary solitary form (-Table 1). ${ }^{3-6}$ To the best of our knowledge, we are reporting second case of

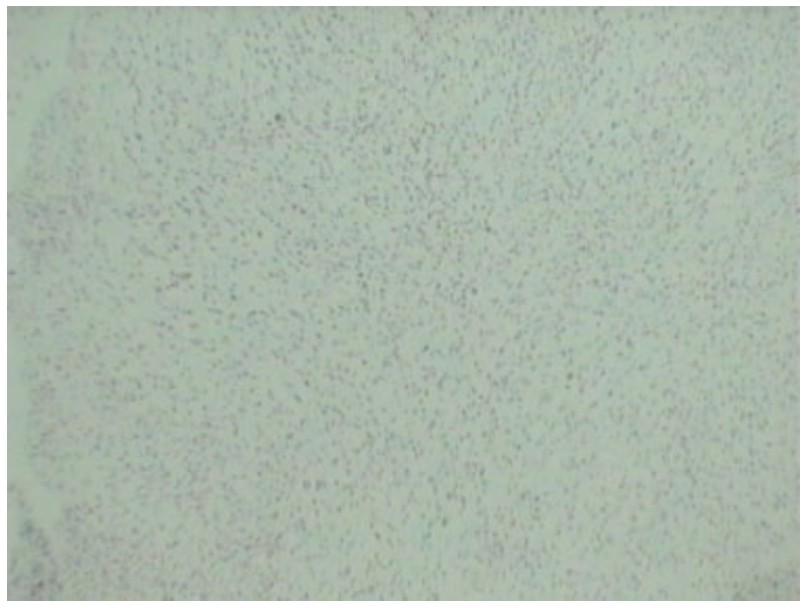

Fig. 2 Desmin-negative.

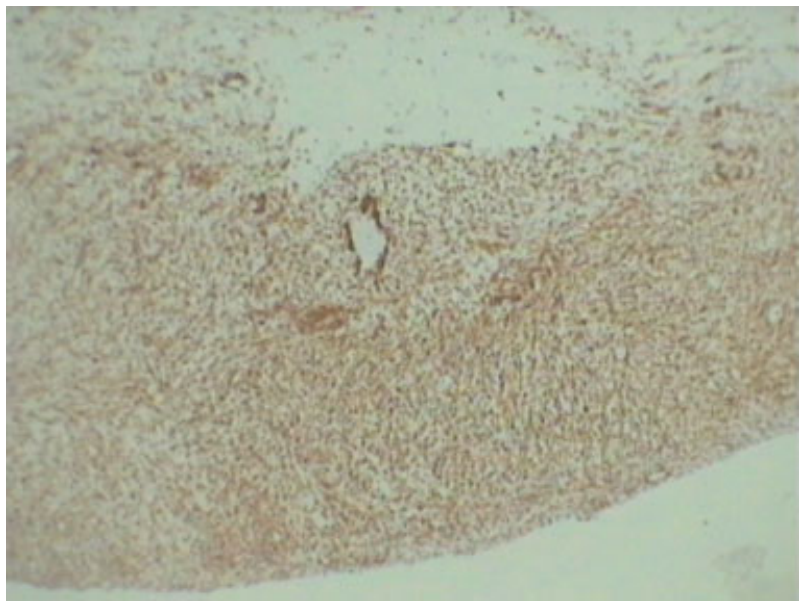

Fig. 3 Smooth muscle actin-positive. 


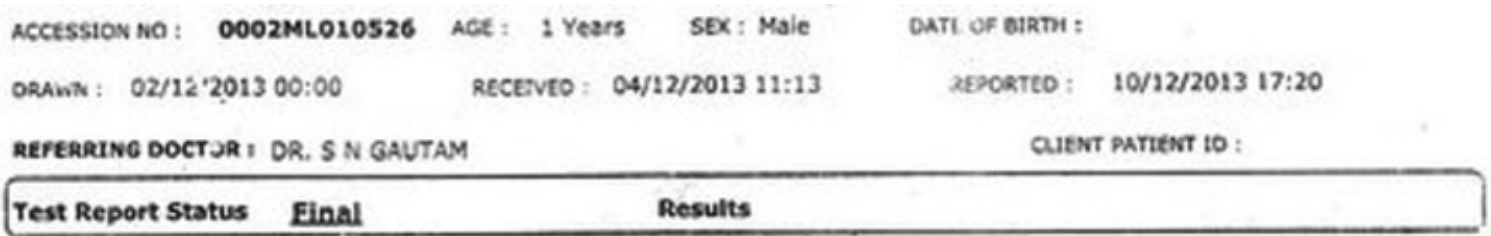

\section{HISTOPATHOLOGY}

\section{CUSTOM IHC PANEL CUSTOM IHC PANEL ADDITIONAL COMMUNICATION}

SPECIMEN M:CROSCOPIC EXAMINATION

\section{DESMINIHC, THSSUE/RARAEFIM BLOCK

Fig. 4 Immunohistopathology report.

intramedullary solitary type IM localized within the spinal cord without any visceral involvement.

The etiology and pathogenesis of IM are still obscure. The solitary form of infantile myofibromatosis mostly occurs in the soft tissues of the head and neck, followed by the upper extremities and trunk. Patients usually have a poor clinical symptomatology, except for occasional pain caused by compression of adjacent nerves. ${ }^{7-9}$

Our patient's symptoms of dribbling of urine and weakness in bilateral lower limbs pointed toward compressive symptoms of tumor in spinal canal.

The usual clinical course of the solitary form is initial rapid growth followed by spontaneous regression within the first 2 years.

Conservative management is usually adopted for those without visceral involvement and complications. We did surgical decompression that was probably the correct decision in our case as literature says that younger patient age at diagnosis is associated with a more rapid expansion rate for infantile myofibromatosis. ${ }^{10}$

In aggressive cases, there is limited experience of success with radiation therapy, different combination of chemotherapy, ${ }^{11,12}$ steroid injection, ${ }^{11,12}$ and $\alpha$ interferon.

\section{Conclusion}

Given the rarity of this condition, correct preoperative diagnosis could not be made initially until after histolopathological examination. Though a rare disorder, IM must be suspected when evaluating children who present with either multiple lytic bone lesion or solitary/multiple tumors in the soft tissues, particularly during the neonatal or infancy period .Early surgical decompression of spinal cord led to improved neurological outcome in the patient with infantile myofibromatosis. 


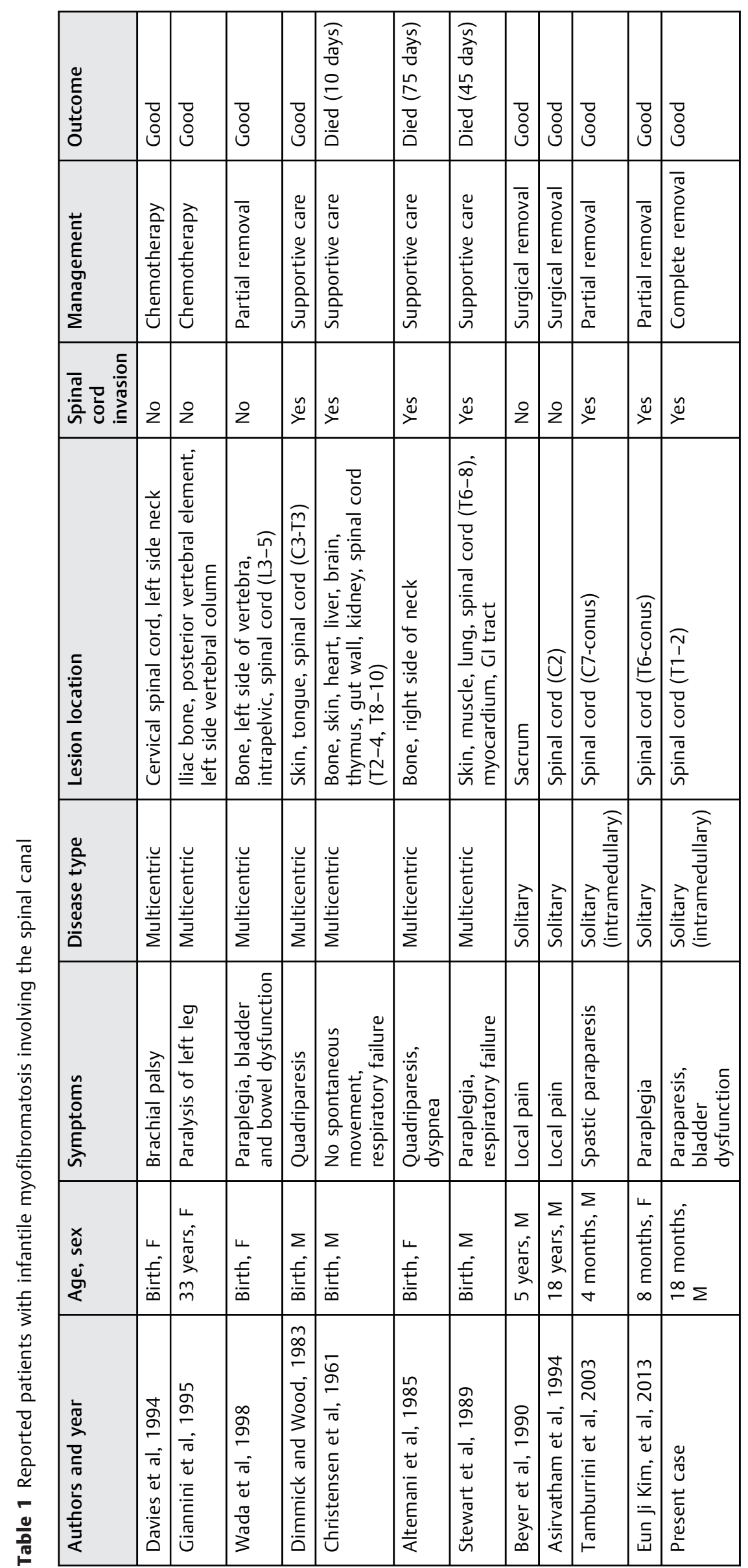




\section{References}

1 Stout AP. Juvenile fibromatoses. Cancer 1954;7(5):953-978

2 Chung EB, Enzinger FM. Infantile myofibromatosis. Cancer 1981; 48(8):1807-1818

3 Beyer WF, Kraus J, Glückert K, Goldmann AR. [Solitary infantile myofibromatosis of the sacrum]. Z Orthop Ihre Grenzgeb 1990; 128(5):473-476(Ger)

4 Asirvatham R, Moreau PG, Antonius JI. Solitary infantile myofibromatosis of axis. A case report. Spine 1994;19(1):80-82

5 Tamburrini G, Gessi M, Colosimo C Jr, Lauriola L, Giangaspero F, Di Rocco C. Infantile myofibromatosis of the central nervous system. Childs Nerv Syst 2003;19(9):650-654

$6 \mathrm{Kim}$ EJ, Wang KC, Lee JY, et al. Congenital solitary infantile myofibromatosis involving the spinal cord. J Neurosurg Pediatr 2013;11(1):82-86

7 Cardia E, Molina D, Zaccone C, la Rosa G, Napoli P. Intracranial solitarytype infantile myofibromatosis. Childs Nerv Syst 1993;9(4):246-249
8 Kaplan SS, Ojemann JGM, Grange DK, Fuller C, Park TS. Intracranial infantile myofibromatosis with intraparenchymal involvement. Pediatr Neurosurg 2002;36(4):214-217

9 Rutigliano JM, Pollack IF. Ahdab- Barmada M, Pang D, LelandAlbright A. Intracranial infantile myofibromatosis. J Neurosurg 1994;81:539-543

10 Roggli VL, Kim HS, Hawkins E. Congenital generalized fibromatosis with visceral involvement. A case report. Cancer 1980;45(5):954-960

11 Holzer-Fruehwald L, Blaser S, Rossi A, Fruehwald-Pallamar J, Thurnher MM. Imaging findings in seven cases of congenital infantile myofibromatosis with cerebral, spinal, or head and neck involvement. Neuroradiology 2012;54(12): 1389-1398

12 Sinha AK, Jesudason EC, Mallucci CL, Losty PD, Kokai G, Pizer BL. Infantile myofibromatosis of the craniovertebral junction. $\mathrm{Br} \mathrm{J}$ Neurosurg 2008;22(4):575-577 